Escuela de Ciencias Sociales y Humanidades, UNED, C.R.

URL: http://investiga.uned.ac.cr/revistas/index.php/espiga/index

ISSN: 1409-4002 • e-ISSN: 2215-454X

\title{
«No tenemos tiempo ni para errores, ni para travesuras políticas»
}

\section{Wilfredo Ricardo Mesa-Ortega*}

(iD https://orcid.org/0000-0002-8704-6743

\section{Carlos A. Santovenia-Pérez**}

iD https://orcid.org/0000-0003-4584-1949

\author{
Recibido: 16 de febrero, 2019 - Aceptado: 18 de julio, 2019
}

\section{RESUMEN}

Se valora cómo la ingente labor política de José Martí, orientada a trabajar por el equilibrio del mundo, la libertad, la paz y el trabajo virtuoso para todos los pueblos, le exigió realizar una profunda valoración de la posición geográfica cubana, elaborar una novedosa concepción geopolítica positiva: solidaria, colaborativa e inclusiva; contrapuesta al hegemonismo, el proteccionismo y la desigualdad que advirtió en la geopolítica negativa del Norte revuelto y brutal, y luchar en

\section{Formato de citación según APA}

Mesa Ortega, W. y Santovenia-Pérez, C. (2019). No tenemos tiempo ni para errores, ni para travesuras políticas. Revista Espiga, 18 (38), 179-195.

\section{Formato de citación según Chicago-Deusto}

Mesa Ortega, Wilfredo Ricardo y Carlos A. Santovenia Pérez (2019). «No tenemos tiempo ni para errores, ni para travesuras políticas». Revista Espiga 18, n. ${ }^{\circ} 38$ (juliodiciembre, 2019): 179-195.

* Doctor en Ciencias Pedagógicas por la Universidad de Matanzas, Cuba. Catedrático de Geografía en la Facultad de Educación de la Universidad de Matanzas. Autor de numerosos artículos sobre la vida, obra y pensamiento de José Martí Pérez en la formación humanística y profesional pedagógica de educadores. En 2015, le fue otorgado el reconocimiento nacional «La Estrella Martiana» por su contribución a los estudios de la obra de José Martí Pérez y a la formación martiana de educadores cubanos. Correo: wilfredoricardo59@gmail.cu

** Máster en Gestión del turismo por la Universidad Internacional de Andalucía y licenciado en Geografía por el Instituto Superior Pedagógico Juan Marinello de Matanzas, Cuba. Profesor titular de turismo (jubilado) en la Facultad de Ciencias Económicas y Empresariales de la Universidad Nacional Autónoma de Nicaragua-León (UNAN-León). Durante casi diez años de su labor profesoral en Cuba, se dedicó al estudio de la presencia de lo geográfico en la obra martiana, así como a la impartición de cursos sobre la vida y obra de José Martí Pérez. Correo: carlosant@yahoo.com 
contra del nefasto destino que preparaba Estados Unidos de América para Cuba, la América y el mundo. Los desequilibrios del siglo XX y de los años transcurridos en el XXI confirman la certeza que tienen las advertencias y concepciones geopolíticas martianas, en tanto que la política llevada a cabo por la Revolución cubana refleja la medida en que se han tomado en cuenta sus alertas para, desde el fiel de América, contribuir al equilibrio del mundo, sin tiempo para errores, ni travesuras politicas.

Palabras clave: José Martí, geopolítica positiva, posición geográfica, equilibrio del mundo.

\section{Introducción}

La patria cubana vive hoy como tantas veces, un momento desafiante y riesgoso para avanzar en su desarrollo económico y sociocultural socialista, aprobado por más del $80 \%$ de la población adulta del país durante el referéndum sobre reformas a la Constitución de la República de Cuba, realizado el 24 de febrero de 2019, fecha del aniversario 124 del inicio de la Guerra de 1895, organizada y fundamentada por José Martí para alcanzar la independencia nacional y construir una república en la que su primera ley fuese el respeto a la dignidad plena del ser humano.

La mayoría de su pueblo se mantiene empeñado en la construcción de una sociedad más justa, próspera y sostenible mediante la actualización de su modelo económico, diseñado en consonancia con la dinámica y los escenarios geopolíticos, socioeconómicos y medioambientales que se divisan a escala nacional, regional y global.

Dicho propósito se pretende alcanzar con la implementación del Plan de Desarrollo Económico y Social del país de cara a 2030, en el que se trazan las pautas nacionales para aproximarse al cumplimiento de los objetivos del desarrollo sostenible planteados por la Organización de las Naciones Unidas (ONU) y, dialécticamente, guiado desde los Lineamientos de la Política Económica y Social del Partido y la Revolución Cubana, reconfigurados mediante un amplio y democrático proceso de debate social ${ }^{1}$.

Desde fecha reciente, la máxima dirección del Estado cubano está a cargo de uno de los hijos de la Revolución y puede que alguien piense en cambios de rumbo o de sistema socioeconómico en el país; pero a diferencia de otros, donde los nuevos gobiernos generan rupturas estremecedoras, la mayoría del pueblo cubano se mantiene firme y esperanzado, procurando alcanzar las metas que demanda su mejora y desarrollo sostenible; iluminado por las ideas de Fidel Castro Ruz, quien en una de sus últimas intervenciones ante la Asamblea Nacional del Poder Popular (parlamento cubano) afirmó2: «Perfeccionaremos lo que debamos perfeccionar, con lealtad meridiana y la fuerza unida, como Martí, Maceo y Gómez, en marcha indetenible».

1. «Lineamientos de la Política Económica y Social del Partido y la Revolución para el período 2016-2021, Consejo de Estado, 22-32, Cuba (2017).

2. Fidel Castro Ruz, «Discurso del líder de la Revolución cubana, Fidel Castro Ruz, en la clausura del $7 \mathrm{mo}$ Congreso del Partido Comunista de Cuba», Consejo de Estado, 2 (2017). 
Por otra parte, hechos y declaraciones recientes del actual gobierno norteamericano, demuestran que la nueva actitud política con respecto a la Cuba socialista, iniciada con el anterior presidente, Barack Obama, va girando $180^{\circ}$ y se evidencia un renacer de la hostilidad, el irrespeto a la soberanía, las campañas mediáticas tergiversadoras de la realidad cubana y se reactivan estrategias genocidas y leyes caducas, reprobadas desde hace muchos años por la abrumadora mayoría de las naciones del mundo.

En momentos históricos como el antes bosquejado, se debe volver a beber en esa fuente inacabable de ideas del bien, de reflexiones, alertas y previsiones que es para los cubanos patrióticos, la obra de José Martí. Su vigencia asombra, conmueve y moviliza en función de participar activamente en la mejora del país. Sus opiniones y proyectos para un mundo mejor facilitan entender la relevancia de las pacíficas batallas, de los principios a los que no se renuncian; sentir la valía del sacrificio cotidiano o heroico y avivar el deseo de ser partícipes protagónicos de estos nuevos tiempos revolucionarios.

El título del presente artículo, «No tenemos tiempo ni para errores, ni para travesuras políticas $»^{3}$, bastaría para ilustrar la importancia de revisitar y actuar en consecuencia con el ideario de Martí, ya que desde los agitados años de 1890 a 1895, sigue alertando sobre la necesidad de ser cada vez más previsores del futuro, sin dejar de ser fieles a lo más auténtico y visceral del legado histórico cubano que se ama. Esta cita martiana, escueta y diáfana como una espada, es uno de los consejos más vigentes del Maestro en la presente coyuntura histórica global y nacional.

Y estas advertencias, consejos o alertas geopolíticas las hace Martí, pensando no solo en Cuba, sino en toda la América y el mundo, porque según él, de la posición geográfica cubana se derivaba una significativa responsabilidad planetaria: contribuir al equilibrio del mundo mediante la práctica de una geopolítica positiva: solidaria, colaborativa e inclusiva; contrapuesta al hegemonismo, el proteccionismo y la desigualdad que advirtió en la geopolítica imperialista del Norte revuelto y brutal, cuyas entrañas conoció sin deslumbramientos y que en la actualidad es mucho más consolidado y globalizador.

En estas breves líneas se pretende revelar que su incansable labor por evadir el nefasto destino que Estados Unidos (EE. UU.)preparaba para la América y el mundo se sustentó, entre otros factores, en la convicción de que Cuba posee una especial significación geoestratégica, de la que emana la grandísima responsabilidad de ayudar al equilibrio entre las diversas naciones, lo cual debía ser un factor clave para guiar su comportamiento político internacional y la construcción de una república justa, laboriosa y abierta al mundo.

El desequilibrado siglo XX, donde en 1953, «parecía que el Apóstol iba a morir en el año de su Centenario» ${ }^{4}$, por tanta afrenta y traición a su legado durante la república neocolonial instaurada después de la intervención norteamericana de 1898 y por los años posteriores al triunfo de la Revolución en 1959,plagados de agresiones, guerra genocida y bloqueos de todo tipo, el resurgimiento de doctrinas hegemónicas e hipócritas teorías para justificar el derecho estadounidense a la supremacía regional y mundial, confirman

3. José Pérez, «Fragmentos entre 1885 y 1895», Obras Completas, Tomo 22, 190 (1991).

4. Fidel Castro Ruz, La historia me absolverá (La Habana: Instituto Cubano del Libro, 1975), 4. 
cuánta certeza conservan estas reflexiones martianas; en tanto que, la geopolítica llevada a cabo por la Revolución cubana y su proyección hacia las Américas y el mundo, refleja la medida en que se han tomado en cuenta sus alertas y concepciones para, desde el fiel de América, contribuir a la construcción de un mundo mejor para quienes lo habitan.

\section{Desarrollo}

José Martí impulsa, con su ideario, los esfuerzos de la nación cubana por construir un mundo mejor, tanto en el ámbito nacional como internacional. Está vivamente presente porque los problemas de la especie humana, que lo desvelaron y sobre los cuales alertó proféticamente, lejos de resolverse se han agudizado en la actualidad y, especialmente, gracias a que muchas de las agudas reflexiones y soluciones científicas, políticas y socioculturales que propuso para resolver esos problemas, conservan su capacidad de respuesta a las necesidades de Cuba y la humanidad toda, desde su fórmula del amor triunfante, propuesta para edificar un nuevo orden social: con todos y para el bien de todos ${ }^{5}$.

Configuró su esférico pensamiento «en tiempos de dispersión, de drásticas mudanzas científicas, políticas, culturales y económicas» ${ }^{6}$, pues fue testigo presencial de vertiginosos cambios bajo las condiciones peculiares del naciente imperialismo estadounidense $\mathrm{y}$, al percatarse de su esencia injusta y hegemónica, asumió una actitud crítica y transformadora, convirtiéndose en una fuente inagotable de ideas para la multilateral batalla actual en pos de un mundo más justo y equilibrado.

En el dinámico contexto político, socioeconómico, tecnológico y cultural de su breve tiempo histórico, puesto que murió en la manigua cubana a los 42 años, José Martí se distinguió por manifestar un brillante pensamiento crítico, sustentado en el procesamiento del increíble volumen de información que demandaba su intensa actividad política, en su capacidad de asociar e integrar asuntos históricos y del espacio geográfico de diversa índole y en su amplia autoformación cultural, alimentada por el ejercicio constante de su humanismo práctico. Atento a todo aquello que pudiera interesar a las personas, se comportó, según Juan Marinello, como una «antena ansiosa, tocada todos los vientos del mundo» ${ }^{7}$.

Su pensamiento y actitud crítica singular se caracterizaron por la asunción de una clara posición transformadora ante la realidad integral de su entorno, expresada en una permanente vocación por indagar, asimilar, dialogar, valorar, divulgar y aplicar los conocimientos, los valores, las actividades, los avances y las mejores prácticas humanistas de su época, en beneficio de toda la humanidad y especialmente de los pueblos localizados al sur del río Bravo, identificados por él como Nuestra América ${ }^{8}$.

5. Wilfredo Mesa Ortega, «Un pensamiento relevante para replantear la actividad científico-técnica en el mundo actual: el de José Martí» (Memorias de Conferencia Internacional «Con todos y para el bien de todos», Palacio de las Convenciones, La Habana, 2005).

6. Suzana Rotker, Fundación de una escritura: las crónicas de José Martí (La Habana: Casa de las Américas, 1992), 241.

7. Juan Marinello Vidaurreta, 18 ensayos martianos (La Habana: Ediciones Unión, 1998), 218.

8. Mesa, «Un pensamiento relevante...», 3 . 
Una de las problemáticas sobre las que Martí entregó reflexiones y soluciones plenas de vigor y energía transformadora para la actualidad se refiere ala valoración de las implicaciones políticas, económicas y socioculturales de la posición geográfica de Cuba. Antonio Núñez Jiménez afirmó que Martí «estudió profundamente las consecuencias de la situación geográfica de Cuba ${ }^{9}$, para fundamentar la guerra necesaria que organizó y para fundar, después de alcanzada la independencia, una república nueva y diferente de las vivenciadas en los países donde residió.

Como resultado de sus meditaciones, pronunció certeros, originales y amistosos juicios, que se apartaron de doctrinas geopolíticas manejadas por los centros de poder de su tiempo histórico (cuya intención es destacar en el presente artículo), sobre las implicaciones de dicha situación espacial: en las Antillas, entre las Américas del norte, del centro y del sur; y entre el Caribe, el Golfo de México y el Atlántico, ubicación que poetizó como el crucero del mundo.

Losenfoques martianos sobre el factor posición geográfica cubana y los deberes difíciles que ella le señala, se revelan más claramente en sus trabajos dedicados a la actividad política: lograr la independencia de Cuba y construir después las bases de una república moral, justa y laboriosa; trabajar por la verdadera emancipación e integración de Nuestra América y denunciar la verdad sobre EE. UU., sus esencias políticas, económicas y, sobre todo, su proyección hegemónica hacia los demás países.

La vigencia de estos enfoques radica en que conservan la vitalidad de la razón, la justicia y el humanismo que hacen falta, en pleno siglo XXI, para continuar la lucha de las ideas y con realizaciones sociales concretas, por un mundo más equilibrado, con posibilidades de futuro decoroso y próspero para todos los pueblos, lo cual no debe ser interpretado como que el Apóstol cubano dejó verdades absolutas, imperecederas ni que todo lo que pensó y dijo mantiene su vigencia a pie juntillas. No se trata de repetir y aprender de memoria lo escrito por Martí, se concuerda con Juan Marinello ${ }^{10}$ en que:

lo que hay que poner de relieve y propagar [sobre Martí] es ese recio deber de estar al día, de penetrar por mano propia en todos los campos, de sentirse, sin excepciones, parte responsable de la humanidad que investiga, espera, piensa y canta; lo que hay que destacar es esa inclinación incambiable de su espíritu a aprender en el libro y en la vida, con el sabio y el que no sabe; esa humildad discipular frente a toda jerarquía legítima, nunca reñida con la conciencia de la propia calidad; esa anchura de mente que en todo busca y halla novedad y aporte, sin renunciar al libre enjuiciamiento.

El ejemplo de su vida, al decir de Ezequiel Martínez Estrada, "es el faro que mejor nos guía». La vitalidad de su pensamiento y su vida casi mística, de notable dimensión poética, es una suerte de "misterio que nos acompaña», como dijera en frase legendaria José Lezama Lima. "Estudiando su obra se aprende la historia, se hayan argumentos para comprender el presente y para encarar el futuro, ese estudio germinal nos conduce

9. Antonio Núñez Jiménez, «La geografía: un arma de combate», Causa, Órgano de la Sociedad Cubana de Geografía, año 1, númerol (1992): 7

10. Marinello, 18 ensayos. 
a la unidad y a la verdad» ${ }^{11}$ y es por ello su vigencia apostólica y revolucionaria en la actualidad cubana.

La noche del 18 de mayo de 1895, antes de caer en combate luchando por Cuba libre al siguiente día, escribió en su carta inconclusa al amigo mexicano Manuel Mercado:

(...) ya estoy todos los días en peligro de dar la vida por mi país y por mi deber-puesto que lo entiendo y tengo ánimos para realizarlo- de impedir a tiempo con la independencia de Cuba que se extiendan por las Antillas los Estados Unidos y caigan, con esa fuerza más, sobre nuestras tierras de América. Cuanto hice hasta hoy, y haré, es para eso ${ }^{12}$.

Indudablemente, para Martí, la Guerra del 95 desbordaba el objetivo inmediato de la independencia, ya que por su posición geográfica, la nueva república tendría una misión: impedir la expansión imperialista hacia Nuestra América, no solo denunciando sus intereses de rapiña y hegemonía, sino también, trabajando por el desarrollo y la integración latinoamericana.

Unos meses antes de su caída, preparado ya para partir a la guerra en Cuba, el 25 de marzo de 1895, José Martí y Máximo Gómez proclaman en tierra dominicana el Manifiesto de Montecristi, donde se subraya la significación de la posición geográfica cubana en el carácter y los alcances de la guerra de independencia y la nueva república que se pretendía construir una vez instaurada la paz. Al respecto, en dicho manifiesto se precisa ${ }^{13}$ :

La guerra de independencia de Cuba, nudo del haz de islas donde se ha de cruzar, en plazo de pocos años, el comercio de los continentes, es suceso de gran alcance humano y servicio oportuno que el heroísmo juicioso de las Antillas presta a la firmeza y trato justo de las naciones americanas y el equilibrio aún vacilante del mundo. Honra y conmueve pensar que cuando cae en tierra de Cuba un guerrero de la independencia... cae por el bien mayor del hombre, la confirmación de la república moral en América, y la creación de un archipiélago libre donde las naciones respetuosas derramen las riquezas que a su paso han de caer sobre el crucero del mundo.

Es evidente que para Martí el ejemplo de una Cuba justa y laboriosa, soberana y distinta de los modelos de repúblicas que existían entonces, contribuiría a consolidar el equilibrio geopolítico no solo en América, sino a escala mundial; y que, consideraba su posición geográfica como una de las riquezas que la naturaleza regaló a los cubanos, con las consecuencias casi todas favorables o desfavorables como el embate de los huracanes, derivadas de dicha posición, ya que la proximidad de EE. UU. no es nefasta por razón geográfica o natural, sino por causa de su prepotencia de gigante egoísta y por los apetitos imperiales de quienes deciden realmente su política.

En su artículo El tercer año del Partido Revolucionario Cubano, publicado en abril de 1894 en Patria, Martí, en su afán de educar informando, se muestra como un conocedor profundo de las entrañas imperialistas del Norte revuelto y brutal, «que por geografía, estrategia, hacienda y política necesita de nosotros» ${ }^{14}$ y lucha por evitar el nefasto destino que preparan

11. Elmys Escribano Hervis, José Martí para educadores (La Habana: Pueblo y Educación, 2011), 72.

12. José Martí Pérez, Obras Completas (La Habana: Editorial de Ciencias Sociales, 1991), 161.

13. Martí, Obras Completas, 100-101.

14. Martí, Obras Completas, 251. 
para Cuba los Estados Unidos y con ella, para Nuestra América y el mundo. Lucha que, además de inspirarse en el amor a su patria y la humanidad en general, se fundamentó en la convicción de que Cuba, junto a Puerto Rico, posee una especial significación geoestratégica.

Estas afirmaciones sobre las ideas geopolíticas de Martí se sustentan en la interpretación de la siguiente cita, donde de modo trascendental expresa sus análisis geopolíticos sobre Cuba en América, desde una actitud solidaria, colaborativa e inclusiva, también hacia EE. UU. Los cubanos nunca deben olvidar que ${ }^{15}$ :

En el fiel de América están las Antillas, que serían, si esclavas, mero pontón de la guerra de una república imperial contra el mundo celoso y superior que se prepara ya a negarle el poder -mero fortín de la Roma Americana-, y si libres- [...]-serían en el continente la garantía del equilibrio, la de la independencia para la América española aún amenazada y la del honor para la gran república del Norte, que en el desarrollo de su territorio- $[\ldots]$-hallará más segura grandeza que en la innoble conquista de sus vecinos menores y en la pelea inhumana que con la posesión de ellas abriría contra las potencias del orbe por el predominio del mundo.

Además de indicar los deberes y oportunidades dados por la situación geográfica, Martí alertó sobre los riesgos de no cumplirlos a tiempo, peligros que se desencadenaron y convirtieron en tristes realidades en la primera mitad del siglo XX, durante la república neocolonial instaurada tras la guerra hispano-cubano-americana, la intervención yanqui en Cuba y la traición al ideario martiano por parte de la burguesía entreguista y ambiciosa que tomó el poder ${ }^{16}$, al anular los enfoques geopolíticos martianos hasta el triunfo revolucionario de 1959, en que la Generación del Centenario, liderada por Fidel Castro Ruz, los rescató y tomó muy en cuenta, al punto de que configuran el espíritu de la actual política exterior cubana.

Martí advierte como antes, pero para hoy, que: «No a mano ligera, sino con conciencia de siglos, se ha de componer la vida nueva de las Antillas redimidas. Se llegará muy alto por la nobleza del fin; o se caerá muy bajo, por no haber sabido comprenderlo. Es un mundo lo que estamos equilibrando: no son solo dos islas las que vamos a libertar» ${ }^{17}$, con lo cual insiste en que se asuma la responsabilidad continental, y evitar errores o improvisaciones políticas poco meditadas, porque consideraba que: «Un error en Cuba, es un error en América, es un error en la humanidad moderna» ${ }^{18}$.

Desde la creación de las Bases de Partido Revolucionario Cubano (PRC), en 1892, se precisó en su artículo tercero que ${ }^{19}$ :

El Partido Revolucionario Cubano reunirá los elementos de revolución hoy existentes y allegará, sin compromisos inmorales con hombre y pueblo alguno, cuantos elementos nuevos pueda, a fin de fundar en Cuba, por una guerra de espíritu y métodos republicanos, una nación capaz de asegurar la dicha durable de sus hijos y de cumplir en la vida histórica del continente, los deberes difíciles que su situación geográfica le señala.

15. Martí, Obras Completas, 142.

16. Mario Mencia López Francisca y Pedro Álvarez, Historia de Cuba 1899-1958; estado nacional, dependencia y revolución (La Habana: Pueblo y Educación, 2012), 141.

17. Martí, Obras Completas, 142.

18. Martí, Obras Completas, 143.

19. Martí, Obras Completas, 279. 
Dicho artículo, al igual que el PRC, faltó en las bases de los partidos gobernantes en la neocolonia, pero su esencia está muy presente en las bases de las organizaciones políticas y sociales que, unidas desde 1959, construyen la sociedad cubana actual: abierta al mundo solidariamente.

Las meditaciones de Martí sobre cómo hacer una guerra breve, poca de sangre y sin odios, estuvieron asociadas a su conciencia plena de las responsabilidades y peligros que emanaban de la posición geográfica de Cuba; próxima a un vecino poderoso que, desde su origen como nación, puso los ojos sobre ella y la considera por naturaleza geográfica como suya, así como a otras repúblicas menores, hermanadas culturalmente, pero plagadas de deformaciones estructurales que limitan su real emancipación y desarrollo integral como naciones. En uno de los fragmentos de cuadernos de apuntes donde hacía notas que utilizaba para elaborar documentos o artículos vinculados a la organización de la guerra, escribió esta reflexión que demuestra lo antes planteado ${ }^{20}$ :

Pensando en cómo será la guerra corta, cómo se ha de hacer todo desde el principio para que con nuestros elementos heterogéneos se produzca el menor mal posible, cómo se ha de organizar la hacienda. Porque nosotros, enclavados como estamos, entre pueblos E. U. e istmo, no tenemos tiempo ni para errores, ni para travesuras políticas. A los traviesos tenemos que desnudarlos. Venimos con los deberes de la mayor edad, y tenemos que probar que somos capaces de ella.

Para Martí, la posición geográfica cubana no solo tiene valor político, socioeconómico y cultural. Este factor también influye en la belleza de sus paisajes naturales, en su benigno clima tropical y hasta en las características idiosincráticas más loables de los cubanos, entre las cuales señalaba la capacidad de admirar el talento y la obra de los grandes creadores. En su artículo Albertini y Cervantes, dedicado a elogiar a estos músicos cubanos, publicado en Patria el 14 de mayo 1892, al pensar en la Cuba futura que soñaba, exclamó, emocionado ${ }^{21}$ :

¡Ah, Cuba, futura universidad americana!: la baña el mar de penetrante azul: la tierra oreada y calurosa cría la mente a la vez clara y activa: la hermosura de la naturaleza atrae y retiene al hombre enamorado: sus hijos, nutridos con la cultura universitaria y práctica del mundo, hablan con elegancia y piensan con majestad, en una tierra donde se enlazarán mañana las tres civilizaciones.

Hoy, el sueño martiano de ver a Cuba convertida en universidad americana, constituye una realidad. Después de 1959, aquí se colabora sin arrogancias ni afán de lucro, con la formación del potencial humanístico y científico-técnico latinoamericano, africano y de otras partes del mundo: son miles los jóvenes de Nuestra América y África, incluso los hay de la América que no es nuestra, que estudian en los centros universitarios cubanos.

No obstante, su valoración fundamental de dicha posición geográfica es por razones políticas; para Martí, estar en el lazo de los mundos es fortaleza de soberanía, universalidad y apertura a todos los pueblos; sustentada en la instauración de una república moral,

20. Martí, Obras Completas, 190-191.

21. Martí, Obras Completas, 413. 
autóctona, justa y distinta de la norteamericana, que percibió claramente: con la libertad como disfraz y la sed de conquista en el corazón, lo cual se evidencia cuando, en Albertini y Cervantes, afirma ${ }^{22}$ :

Más bello será vivir en el lazo de los mundos, con la libertad fácil en un país rico y trabajador, como pueblo representativo y propio donde se junta al empuje americano el arte europeo que modera su crudeza y brutalidad, que rendir el alma nativa, a la vez delicada y fuerte, a un espíritu nacional ajeno que contiene solo uno de los factores del alma de la Isla -que vaciaría en la isla pobre y venal los torrentes de su riqueza egoísta y corruptora- que convertiría un pueblo fino y de glorioso porvenir en lo que Inglaterra ha convertido el Indostán.

Según su juicio geopolítico, diferente del que reinaba en los países imperiales, acostumbrados a expandirse y dominar a otros más débiles, el estar próximos a EE. UU. no era razón para el anexionismo, sino a favor del equilibrio y la libertad, mediante la firme defensa de valores opuestos a los que prevalecen allá, desde que Washington divagó al decir: "Cuánta tierra hay en América y cuántos mares la rodean son natural dominio de esta América del Norte, a quien el suelo y el agua del continente han de acatar como pupilos perdurables ${ }^{23}$.

Sus crónicas, escritas para los países de Nuestra América, fundaron la mejor tradición antiimperialista americana, con profundas argumentaciones y lógicos razonamientos basados en la historia y la cultura ${ }^{24}$. En su artículo El remedio anexionista, publicado en julio de 1892, combatió las tendencias de anexión subsistentes en cubanos, españoles y norteamericanos que no veían a Cuba capaz de manejar su independencia y destacó los riesgos de errar en la construcción de la república cubana, la necesidad de demostrar su capacidad de organización para alcanzar la victoria y puso en claro el desacuerdo con sus intenciones geopolíticas imperiales, de que por ubicación geográfica, el suelo cubano debía ser trampolín o atalaya para la disimulada agresión a las hermanas repúblicas de Latinoamérica $^{25}$. En este sentido, sus palabras fueron ${ }^{26}$ :

Pero el único modo de quitar razón a los cubanos, y a los españoles, que de buena fe creen en nuestra incapacidad para el gobierno propio -aunque creen en la capacidad tan luego como nos liguemos con un pueblo diverso del nuestro, y que tiene sobre nuestro país miras distintas de las nuestras, miras de factoría y de pontón estratégico- es demostrarles, con nuestra organización y victoria, que no todos los cubanos se contentan con fiar a Cuba al capricho del azar, o a la política de espera de una república que se declara ya agresiva, y nos comprende, como puesto de defensa necesaria en su plan de agresión.

Uno de los momentos anteriores a la preparación de la Guerra Necesaria (de 1995) en que más brilló el pensamiento geopolítico de Martí, fue cuando en la Conferencia Monetaria de las Repúblicas de América (convocada por EE. UU. en 1891), se constituyó una

22. Ibid., 413 .

23. Martí, Obras Completas, 239.

24. Escribano, José Martí para..., 21.

25. Eduardo Torres-Cuevas y Óscar Loyola Vega, Historia de Cuba 1492-1898, formación y liberación de la nación (La Habana: Pueblo y Educación, 2001), 136.

26. Martí, Obras Completas, 49-50. 
victoriosa batalla diplomática, ya que asistió como cónsul de Uruguay. En ella cuestionó, desenmascaró y arremetió contra las veladas intenciones hegemónicas del hipócrita anfitrión, al denunciar enérgicamente que ${ }^{27}$ :

Creen en la necesidad, en el derecho bárbaro, como único derecho: 'Esto es nuestro porque lo necesitamos'. Creen en la superioridad incontrastable de 'la raza anglosajona contra la raza latina'. Creen en la bajeza de la raza negra, que esclavizaron ayer y vejan hoy, y de la india, que exterminan. Creen que los pueblos de Hispanoamérica están formados, principalmente, de indios y de negros. Mientras no sepan más de Hispanoamérica los Estados Unidos y la respeten más (...) ¿pueden los Estados Unidos convidar a Hispanoamérica a una unión sincera y útil para Hispanoamérica? ¿Conviene a Hispanoamérica la unión política y económica con los Estados Unidos?

Quien dice unión económica dice unión política. El pueblo que compra, manda. El pueblo que vende, sirve. Hay que equilibrar el comercio, para asegurar la libertad. El pueblo que quiere morir, vende a un solo pueblo, y el que quiere salvarse, vende a más de uno. El influjo excesivo de un país en el comercio de otro, se convierte en influjo político.

El trascendental análisis histórico, geopolítico y económico en que se basó el descubrimiento martiano de las verdaderas intenciones norteamericanas en dicha conferencia regional, lo condujo a rechazar radicalmente la idea de que la situación geográfica deba implicar subordinación y dependencia de los países menos desarrollados con respecto a las potencias cercanas y a plantear principios de plena validez actual, para consolidar a Nuestra América como zona de paz en el siglo XXI; en este sentido señaló ${ }^{28 .}$

El caso geográfico de vivir juntos en América no obliga, sino en la mente de algún candidato o algún bachiller a unión política (...) La unión, con el mundo y no con una parte de él; (...) Si algún oficio tiene la familia de repúblicas de América, no es ir de arria de una de ellas contra las repúblicas futuras.

No obstante su rechazo a la celada política y financiera orquestada por EE. UU. a los países de Latinoamérica con esta Conferencia Monetaria Panamericana, José Martí aprovechó para aplaudir toda acción sincera, de acercamiento solidario y respetuoso entre los países de América y el mundo, al afirmar ${ }^{29}$ : «Ha de procurarse la moneda uniforme. Ha de hacerse cuanto prepare a ella (...) Ha de desearse, y de ayudar a realizar, cuanto acerque a los hombres y les haga la vida más moral y llevadera. Ha de realizarse cuanto acerque a los pueblos».

La angustia de Martí frente a la rapacidad demostrada por EE. UU. hacia Nuestra América desde su cuna como nación independiente, combinada con la falta de integración y acciones de progreso en los países al sur del río Bravo, que los hacía muy vulnerables ante este vecino poderoso, arrogante y pragmático en demasía, se manifestó con toda nitidez desde 1889, cuando tuvo lugar el Congreso Internacional de Washington, plagado de las intenciones hegemónicas y neocoloniales que develó y criticó severamente.

27. Martí, Obras Completas, 160.

28. Ibid., 160

29. Martí, Obras Completas, 161. 
Desde sus primeras cartas sobre dicho congreso a La Nación de Buenos Aires, Martí pone en alerta a los países del sur sobre los riesgos y vilezas que encerraba dicho cónclave panamericano convocado por EE. UU. ${ }^{30}$ :

Jamás hubo en América, de la independencia acá, asunto que requiera más sensatez, ni obligue a más vigilancia, ni pida examen más claro y minucioso, que el convite que los Estados Unidos potentes, repletos de productos invendibles, y determinados a extender sus dominios en América, hacen a las naciones americanas de menor poder, ligadas por el comercio libre y útil con los pueblos europeos, para ajustar una liga con Europa y cerrar tratos con el resto del mundo (...), después de ver con ojos judiciales los antecedentes, causas y factores del convite, urge decir, porque es la verdad, que ha llegado para la América española la hora de declarar su segunda independencia.

Frente a la falta de unidad y la superficialidad con que representantes de los países latinoamericanos esperaban a que iniciaran las sesiones del congreso y para contrarrestar la avalancha de ideas panamericanistas que se publicaban con desfachatez en la prensa norteamericana a favor de EE. UU., José Martí hace un análisis geopolítico de las Américas y plantea una interrogante que conserva gran vigencia en este siglo XXI, debido a que ocurrió lo que él temía que pasara y la situación sigue muy parecida en términos generales: luchando por la integración latinoamericana, la Organización de Estados Americanos (OEA) está corrupta, se revitaliza arrogantemente la Doctrina Monroe y las Cumbres de las Américas conservan las nefastas intenciones de este congreso de 1889. En otra de sus cartas a La Nación, Martí precisa y pregunta ${ }^{31}$ :

De una parte hay en América un pueblo que proclama su derecho de propia coronación a regir, por moralidad geográfica, en el continente y anuncia (...) que todo el norte de América ha de ser suyo, y se le ha de reconocer derecho imperial del istmo abajo, y de otra están los pueblos (...) que no tienen más enemigo real que su propia ambición, y la del vecino que los convida a ahorrarle el trabajo de quitarles mañana por la fuerza lo que le pueden dar de grado ahora. ¿Y han de poner sus negocios los pueblos de América en manos de su único enemigo, o de ganarle tiempo, y poblarse, y unirse, y merecer definitivamente el mérito de las naciones, antes de que ose demandarles la sumisión (...) por la razón de estar en un mismo continente?

El estudio realizado permite afirmar que la genialidad de los enfoques de Martí sobre las múltiples implicaciones de la posición geográfica cubana y los deberes quele indica, se expresó gracias a su estrecha interrelación con otras dimensiones de su exuberante pensamiento crítico, entre las que merecen destacarse las siguientes ${ }^{32}$ :

- El estudio, valoración y divulgación de la vida y obra de relevantes figuras vinculadas a la política, el arte, las ciencias y el quehacer humano ${ }^{33}$.

- El entusiasmo y profundidad con que reflexionó sobre eventos políticos, científicos, descubrimientos, innovaciones tecnológicas, publicaciones y proyectos de desarrollo.

30. Martí, Obras Completas, 46.

31. Martí, Obras Completas, 56.

32. Mesa Ortega, «Juicios martianos...», 5.

33. Wilfredo Mesa Ortega, «Científicos de la geografía en la obra escrita de José Martí Pérez», Honda, revista de la Sociedad Cultural José Martí, número 32 (2011): 60-62. 
- La agudeza, belleza y objetividad de sus observaciones y descripciones de la naturaleza, la vida socioeconómica y cultural de los lugares donde estuvo presente y de otros que conoció mediante sus abundantes lecturas y conversaciones.

- Su insistencia en una educación emancipadora, para ser cada vez más cultos y libres, concepción que incluye educar para la paz y la prosperidad de los pueblos.

- La objetividad de su contraste entre las realidades y diferencias esenciales entre la América latina y la América anglosajona, donde deja ver que su apego a los pobres de la tierra deriva, entre otras razones, de su rechazo a la miseria espiritual apreciada en medio de la opulencia material del norte revuelto y brutal.

- La valoración crítica de la enseñanza de su época, proponiendo que la educación científica desterrara a la escolástica y libresca o excesivamente pragmática de entonces, con el estudio de materias importantes para educar el juicio crítico, el humanismo solidario y el sentido de pertenencia y compromiso social con el contexto sociocultural en que se vive.

El estudio del contexto histórico en que vivió José Martí permite puntualizar factores que se combinaron para dar origen a la vasta cultura geopolítica positiva del apóstol cubano, de América y el mundo, entre los que sobresalen ${ }^{34}$.

- El haber asistido a una escuela básica con una relativamente buena educación geográfica que enriqueció de forma autodidacta y le sembró el gusto por los mapas.

- Su espíritu integrador, atento a todo lo que pueda interesar al género humano y a mejorar las condiciones de su vida, lo condujo a vincular lo natural con lo social y percatarse de la interconexión entre todo lo que acontece en el espacio geográfico en cada momento histórico concreto.

- El acopio y procesamiento eficaz de vivencias socioculturales a través de su elevada sensibilidad hacia el paisaje cultural en general.

- Su humanismo de profunda raíz cristiana y a la vez cosmopolita, desbordado en su amor a los humildes y el desapego a los déspotas y tiránicos.

- Su destacada e innovadora labor periodística, orientada a la educación integral de personas libres, cultas y virtuosas, sobre todo en la Latinoamérica que conoció y amó como su patria grande.

- Su activa y patriótica estancia en Nueva York -el mirador universal de su época- le posibilitó hacer valoraciones y proponer soluciones duraderas y justas para Cuba y Nuestra América e, incluso, para los norteamericanos.

- Su carácter de hombre político, entregado a la independencia de Cuba y a la descolonización cultural de la América mestiza, lo condujo a estudiar la historia, la naturaleza, el presente y a soñar un futuro digno y sustentable para todos los pueblos.

34. Mesa Ortega, «Juicios martianos...», 3. 
- El auge de las ciencias naturales, la filosofía y otras ciencias humanas en la segunda mitad del siglo XIX, integradoras de lo natural y lo social como la geografía, no escapó a su estudio y reflexión creadora.

La comprensión de la genialidad martiana con respecto a las implicaciones políticas de la situación geográfica de Cuba requiere no solo conocer cuáles fueron las posiciones asumidas por el gran cubano, sino analizar también cuáles eran las tendencias de pensamiento geopolítico dominantes en su época y cómo las criticó, lo que necesariamente demanda hacer referencia a la instauración de la llamada escuela geográfica en la sociología del siglo XIX ${ }^{35}$, escuela caracterizada por el determinismo geográfico, una corriente de pensamiento cuyas teorías alcanzaron reconocimiento universal, producto del auge y popularidad alcanzada por las ciencias geográficas, fundamentalmente en la segunda mitad del siglo XIX ${ }^{36}$.

En esencia, el determinismo geográfico fue una corriente de pensamiento paradigmática en el siglo XIX, ya que permeó las bases teóricas de muchas actividades humanas. Actualmente está superada por el análisis marxista de la relación naturaleza-sociedad o ambiente-desarrollo, quedando como uno de los factores o condiciones que influyen pero que no determinan en los procesos socioeconómicos y culturales, pero que tuvo una amplia aceptación durante el nacimiento del imperialismo como fase del desarrollo capitalista, pues le favorecía a sus intereses políticos expansionistas.

Comprende un conjunto de teorías que pretenden explicar la vida económica, política y social de los países a partir de sus condiciones naturales, es decir, determinadas por la naturaleza. Una de sus variantes «supedita la supervivencia de las naciones o las culturas con su capacidad de expansión y de mejorar su posición geográfica» ${ }^{37}$. Precisamente la política norteamericana se aprovechó de estas teorías para fundamentar «científicamente» sus ambiciones imperiales. Basados en el determinismo geográfico justificaban su derecho a la supremacía en América.

Como bien señala Antonio Núñez Jiménez ${ }^{38}$, la originalidad geopolítica martiana radica en que en una época donde todavía Friedrich Ratzel no había publicado su Politische Geografhie (1897), obra que los fascistas hitlerianos esgrimieron en la primera mitad del siglo XX para fundamentar su superioridad cultural y necesidad de espacio vital, nuestro Martí elaboró una brillante síntesis de las implicaciones políticas de la geografía antillana, contrapuesta al determinismo geográfico defendido por el imperialismo norteamericano, ya que «sus enfoques y concepciones están en función de hacer más libre a la humanidad y consolidar el equilibrio del mundo, por lo que nos legó una geopolítica positiva, que se contrapone a toda dominación y supremacía, sea por causas naturales o histórico-sociales del desarrollo de los países».

35. James Tyndall, La evolución histórica de las ideas cientificas (Madrid: Imprenta Rollo, 1988), 39.

36. Francisco Zaragoza, José Martí y las ciencias naturales de su época (La Habana: Editorial Academia, 1996), 22.

37. Ivanov Kow, Historia de la sociología del siglo XIX - comienzos del XX (Moscú: Editorial Progreso, 1989), 65.

38. Núñez Jiménez, La geografia ..., 8. 
Estas consideraciones martianas fueron un duro golpe para la variante criolla del determinismo geográfico que los entreguistas de ayer y los que hoy subsisten, utilizan para justificar la anexión de Cuba a EE. UU., conocida como fatalismo geográfico, según la cual Cuba está predestinado, por su cercanía geográfica, a ser un estado más o una neocolonia del imperio yanqui, olvidando la historia, la cultura, las decisiones soberanas y los problemas comunes que unen a la isla con América y con todos los pueblos del sur y el mundo.

Cuba, con su revolución, sigue atenta a los problemas del país y de todos los países, previendo el futuro, fiel a su historia más auténtica y progresista, abierta a los cambios, pero fortaleciendo su identidad y sus conquistas con espíritu solidario y de lucha por un mundo gobernado democráticamente; se mantiene fiel al legado martiano, aplica, consolida y enriquece sus ideas acerca de las responsabilidades que le plantea su posición geográfica en el crucero del mundo y ofrece un ejemplo concreto, potencialmente transferible a toda la humanidad, de lo mucho que aún queda por hacer para que gobierne lo que, según José Martíî, «todos los pueblos tienen (...) de majestuoso y de común, más vasto que el cielo, más grande que la tierra, más luminoso que las estrellas, más ancho que el mar: el espíritu humano».

\section{Conclusiones}

- El amor de José Martí a Cuba y Nuestra América, sus intensas vivencias, su quehacer como periodista, su estancia activa en Nueva York, su vasta cultura y su incansable labor política en función de mejorar el mundo y a las personas, le posibilitaron elaborar concepciones geopolíticas que conservan plena vigencia y juegan un papel orientador fundamental, en las relaciones de Cuba con el mundo actual; las cuales son bien distintas de las manejadas históricamente por los gobiernos estadounidenses.

- En el empeño de seguir las huellas del desarrollo de sus concepciones geopolíticas se aprecia que José Martí transitó desde la comprensión del determinismo geográfico que prevaleció en su época a favor de las nacientes potencias imperialistas, hasta la elaboración de ideas geopolíticas de contenido y sentido diferentes, cuyo objetivo era contribuir al equilibrio del mundo, al poner freno y levantar una muralla, con el decoro firme y la sagaz independencia, a los apetitos hegemónicos del naciente imperialismo norteamericano a finales del siglo XIX.

- La situación socioeconómica y política de la región latinoamericana y del mundo actual, refleja la certeza de muchas advertencias de José Martí relacionadas con los peligros de vivir próximos a una potencia imperial de monstruosas entrañas morales. Su legado apostólico indica al pueblo cubano que el camino al futuro no está en claudicar y bajar las banderas históricas de sus luchas por construir la patria que soñó, sino en actualizar y renovar permanentemente su modelo de desarrollo sostenible y en continuar la batalla de ideas y realizaciones concretas que evidencien la justeza de su orientación política socialista, humanista y martiana.

39. Martí, Obras Completas, 361. 
- Cuba, junto con otros países y fuerzas revolucionarias, se mantiene en el fiel de América, consciente y empeñada en cumplir la responsabilidad planetaria emanada de su peculiar localización geográfica: contribuir al equilibrio del mundo y sigue sin tiempo para errores, ni travesuras políticas, tal y como alertó Martí, ya que el águila imperial se mantiene al acecho y presta al acoso de todo el que no se alinee a sus designios, mucho más agresiva y arrogante que cuando Martí la conoció visceralmente en las décadas finales del siglo XIX.

\section{ABSTRACT}

«No time for errors or political shenanigans»

The article explores how the political labor of Jose Marti, oriented towards fighting for the world's equilibrium, peace, and job opportunities for everybody, demanded of him a deep assessment of the Cuban geographical position, elaborate a novel conception of positive geopolitics: supportive, collaborative, and inclusive; opposed to the hegemonies, protectionism and inequality he saw in the negative geopolitics of the brutal and turbulent North, and fight against the disastrous destiny that the United States was preparing for Cuba, Latin America, and the world. The disparities of the $20^{\text {th }}$ century and the passing years of the $21^{\text {st }}$, confirm the certainty of Marti's warnings and geopolitical conceptions. The politics of the Cuban Revolution reflect the degree to which Marti's warnings have been taken into account to, from the faithful of America, contribute to world's equilibrium, with no time for errors or political shenanigans.

Key words: Jose Marti, positive geopolitics, geographical position, world equilibrium.

\section{RÉSUMÉ}

\section{"Nous n'avons temps ni pour erreurs ni pour espiègleries politiques"}

Cet article met en valeur l'action politique si importante de José Martí, laquelle était orientée vers l'équilibre du monde, la liberté, la paix et le travail virtuose pour tous les peuples. Son travail politique exigeait réévaluer exhaustivement la position géographique cubaine et élaborer une nouvelle conception géopolitique positive : solidaire, collaboratrice et inclusive, opposée à l'hégémonisme, le protectionnisme, l'inégalité qui ont été perçus dans la géopolitique négative de l'Amérique du Nord convulsé et brutal. Il a aussi lutté contre le destin néfaste que les Etats-Unis d'Amérique préparait pour le Cuba, l'Amérique et le monde. Les déséquilibres du XX ${ }^{\text {ème }}$ siècle et des années vécus du XXI ${ }^{i m e}$ siècle confirment la certitude des avertissements et des conceptions géopolitiques de Martí. D’autre part, la politique menée par la Révolution cubaine reflète les mesures qui prennent compte des alertes du fidèle d'Amérique afin de contribuer à l'équilibre du monde, sans temps pour erreurs ni espiègleries politiques.

Mots clés: José Martí, géopolitique, position géographique, équilibre du monde.

\section{Referencias bibliográficas}

Castro Ruz, Fidel. Discurso del líder de la Revolución cubana, Fidel Castro Ruz, en la clausura del 7mo. Congreso del Partido Comunista de Cuba, 2017. Consejo de Estado. La Habana.

Castro Ruz, Fidel. La historia me absolverá. La Habana: Instituto Cubano del Libro, 1975. 
Cuba. Documentos del 7mo. Congreso del Partido aprobados por el III Pleno del Comité Central del PCC el 18 de mayo de 2017 y respaldados por la Asamblea Nacional del Poder Popular el 1 de junio de 2017 (I). Consejo de Estado. La Habana.

Escribano Hervis, Elmys. José Martí para educadores. La Habana: Editorial Pueblo y Educación, 2011.

Kow, Ivanov. Historia de la sociología del siglo XIX - comienzos del XX. Moscú: Editorial Progreso, 1989.

Francisca López, Mario Mencia y Pedro Álvarez. Historia de Cuba 1899-1958; estado nacional, dependencia y revolución. La Habana: Editorial Pueblo y Educación, 2012.

MarinelloVidaurreta, Juan. 18 ensayos martianos. La Habana: Ediciones Unión, 1998.

Martí Pérez, José. Obras Completas. Tomo 4. Albertini y Cervantes. Patria 14 de mayo 1892. La Habana: Editorial de Ciencias Sociales, 1991.

Martí Pérez, José. Obras Completas. Tomo 6. Congreso internacional de Washington. 1889. A la Nación. La Habana: Editorial de Ciencias Sociales, 1991.

Martí Pérez, José. Obras Completas. Tomo 6. Extranjero. La Habana: Editorial de Ciencias Sociales, 1991.

Martí Pérez, José. Obras Completas. Tomo 6. La conferencia monetaria de las repúblicas de América. 1891. La Habana: Editorial de Ciencias Sociales, 1991.

Martí Pérez, José. Obras Completas. Tomo 1. La Habana: Editorial de Ciencias Sociales, 1991.

Martí Pérez, José. Obras Completas. Tomo 2. El remedio anexionista. Patria. Julio 1892. La Habana: Editorial de Ciencias Sociales, 1991.

Martí Pérez, José. Obras Completas. Tomo 20. Carta a Manuel Mercado, 18 de mayo 1895. La Habana: Editorial de Ciencias Sociales, 1991.

Martí Pérez, José. Obras Completas. Tomo 22. Fragmentos entre 1885 y 1895. La Habana: Editorial de Ciencias Sociales, 1991.

Martí Pérez, José. Obras Completas. Tomo 3. Bases del Partido Revolucionario Cubano. Artículo 3ro. 1892. La Habana: Editorial de Ciencias Sociales, 1991.

Martí Pérez, José. Obras Completas. Tomo 3. El tercer año del Partido Revolucionario Cubano. Abril, 1894. La Habana: Editorial de Ciencias Sociales, 1991.

Martí Pérez, José. Obras Completas. Tomo 4. Manifiesto de Montecristi, 25 de marzo 1895. La Habana: Editorial de Ciencias Sociales, 1991.

Mesa Ortega, Wilfredo. «Científicos de la geografía en la obra escrita de José Martí Pérez». Honda, revista de la Sociedad Cultural José Martí, n. ${ }^{\circ} 32$ (2011): 60-62.

Mesa Ortega, Wilfredo. «Un pensamiento relevante para replantear la actividad científico-técnica en el mundo actual: el de José Martí». Conferencia internacional «Con todos y para el bien de todos». Palacio de las Convenciones, La Habana, 2005.

Mesa Ortega, Wilfredo y Carlos A. Santovenia Pérez. Juicios martianos de interés geográfico. 2002.

Informe de investigación. Instituto Superior Pedagógico Juan Marinello. Documento en formato digital. Matanzas.

Navarro Cantón, José y Arnaldo Silva León. Historia de Cuba 1959-1999, liberación nacional y socialismo. La Habana: Editorial Pueblo y Educación, 2008.

Núñez Jiménez, Antonio. «La geografía: un arma de combate». Causa, Órgano de la Sociedad Cubana de Geografía, año 1, n. ${ }^{\circ} 1$ (1992). 
Rotker, Suzana. Fundación de una escritura: las crónicas de José Martí. La Habana: Casa de las Américas, 1992.

Torres-Cuevas, Eduardo y Óscar Loyola Vega. Historia de Cuba 1492-1898, formación y liberación de la nación. La Habana: Editorial Pueblo y Educación, 2001.

Tyndall, James. La evolución histórica de las ideas científicas. Madrid: Imprenta Rollo, 1988.

Zaragoza, Fernando. José Martí y las ciencias naturales de su época. La Habana: Editorial Academia, 1996. 